\title{
Estimating the normal background rate of species extinction
}

de Vos, Jurriaan M ; Joppa, Lucas N ; Gittleman, John L ; Stephens, Patrick R ; Pimm, Stuart L

DOI: https://doi.org/10.1111/cobi.12380

Posted at the Zurich Open Repository and Archive, University of Zurich ZORA URL: https://doi.org/10.5167/uzh-98443

Journal Article

Accepted Version

Originally published at:

de Vos, Jurriaan M; Joppa, Lucas N; Gittleman, John L; Stephens, Patrick R; Pimm, Stuart L (2015).

Estimating the normal background rate of species extinction. Conservation Biology, 29(2):452-462.

DOI: https://doi.org/10.1111/cobi.12380 


\title{
Estimating the Normal Background Rate of Species Extinction
}

\author{
JURRIAAN M. DE VOS,${ }^{*} \dagger$ LUCAS N. JOPPA, $\neq$ JOHN L. GITTLEMAN,, PATRICK R. STEPHENS,, \\ AND STUART L. PIMM** \\ *Institute of Systematic Botany, University of Zurich, Zollikerstrasse 107, 8008, Zürich, Switzerland \\ †Department of Ecology and Evolutionary Biology, Brown University, Box G-W, Providence, RI, 02912, U.S.A. \\ $\ddagger$ Microsoft Research, 21 Station Road, Cambridge CB1 2FB, United Kingdom \\ §Odum School of Ecology, University of Georgia, Athens, GA, 30602, U.S.A. \\ **Nicholas School of the Environment, Duke University, Durham, NC, 27708, U.S.A., email stuartpimm@me.com
}

\begin{abstract}
A key measure of humanity's global impact is by bow much it has increased species extinction rates. Familiar statements are that these are 100-1000 times pre-human or background extinction levels. Estimating recent rates is straightforward, but establishing a background rate for comparison is not. Previous researchers chose an approximate benchmark of 1 extinction per million species per year (E/MSY). We explored disparate lines of evidence that suggest a substantially lower estimate. Fossil data yield direct estimates of extinction rates, but they are temporally coarse, mostly limited to marine hard-bodied taxa, and generally involve genera not species. Based on these data, typical background loss is 0.01 genera per million genera per year. Molecular phylogenies are available for more taxa and ecosystems, but it is debated whether they can be used to estimate separately speciation and extinction rates. We selected data to address known concerns and used them to determine median extinction estimates from statistical distributions of probable values for terrestrial plants and animals. We then created simulations to explore effects of violating model assumptions. Finally, we compiled estimates of diversification-the difference between speciation and extinction rates for different taxa. Median estimates of extinction rates ranged from 0.023 to 0.135 E/MSY. Simulation results suggested over-and under-estimation of extinction from individual phylogenies partially canceled each other out when large sets of phylogenies were analyzed. There was no evidence for recent and widespread pre-buman overall declines in diversity. This implies that average extinction rates are less than average diversification rates. Median diversification rates were 0.05-0.2 new species per million species per year. On the basis of these results, we concluded that typical rates of background extinction may be closer to $0.1 \mathrm{E} / \mathrm{MSY}$. Thus, current extinction rates are 1,000 times bigher than natural background rates of extinction and future rates are likely to be 10,000 times bigher.
\end{abstract}

Keywords: diversification rates, extinction rate, fossil record, lineages through time, molecular phylogenies

Estimación de la Tasa Normal de Extinción de Especies

Resumen: Una medida clave del impacto global de la bumanidad es cuánto han incrementado las tasas de extinción de las especies. Las declaraciones conocidas establecen que estas son 100 - 1,000 veces los niveles de extinción pre-bumanos o de fondo. Estimar las tasas recientes es un proceso directo, pero establecer una tasa de fondo para comparar no lo es. Investigadores previos han elegido un punto de referencia aproximado de una extinción por millón de especies por año (E/MEA). Exploramos líneas dispares de evidencia que sugieren un estimado sustancialmente más bajo. Los datos fósiles producen estimados directos de las tasas de extinción, pero son temporalmente burdos, en su mayoría limitados a los taxones marinos de cuerpos duros, 
y generalmente involucran a los géneros y no a las especies. Basándonos en estos datos, la pérdida de fondo típica es de 0.01 géneros por millón de géneros por año. Las filogenias moleculares están disponibles para más taxones y ecosistemas, pero se debate si pueden usarse para estimar por separado las tasas de extinción y especiación. Seleccionamos datos para dirigirnos a asuntos conocidos y los usamos para determinar los estimados de extinción medios a partir de distribuciones estadísticas de valores probables para plantas y animales terrestres. Después creamos simulaciones para explorar los efectos de las suposiciones del modelo de violación. Finalmente, recopilamos los estimados de diversificación - la diferencia entre las tasas de especiación y extinción para taxones diferentes. Los estimados medios de las tasas de extinción variaron desde 0.023 hasta 0.135 E/MEA. Los resultados de la simulación sugirieron una sobre- y subestimación de la extinción a partir filogenias individuales que se cancelaron unas a otras cuando se analizaron conjuntos grandes de filogenias. No bubo evidencia de declinaciones generales pre-humanas, recientes y extensas en la diversidad. Esto implica que las tasas de extinción promedio son menores a las tasas de diversificación promedio. Las tasas medias de diversificación fueron 0.05 - 0.2 especies nuevas por millón de especies por año. Con base en estos resultados, concluimos que las típicas tasas de extinción de fondo pueden ser más cercanas a 0.1 E/MEA. Así, las tasas de extinción actuales son mil veces más altas que las tasas naturales de extinción de fondo y que las tasas futuras probablemente sean 10, 000 veces más altas.

Palabras Clave: filogenias moleculares, linajes a través del tiempo, registro fósil, tasa de diversificación, tasa de extinción

\section{Introduction}

... a mass extinction crisis, with a rate of extinction now 1,000 times higher than the normal background rate.

Al Gore (2006)

Some quantitative statement about the current extinction crisis is needed. As Gore's remark exemplifies, it has become standard to quantify present extinctions as rates and then to compare them to some background that typifies geological history. Mass extinction events are understood to be exceptional events when extinction rates are episodically much higher. Gore follows Pimm et al. (1995) who estimated "recent extinction rates are 100 to 1000 times their pre-human levels." Comparing current and background extinction rates raises a series of issues that we address in this article. Estimating the current rates of extinctions is straightforward (Pimm et al. 1995, 2006, 2014). Here, we explored the more difficult task of estimating the background rate of extinction. By this, we mean the geologically recent rate of extinction before human actions inflated them.

Three data sources bear on the background rate: the fossil record, the overall diversification rates of species, and the detailed patterns of how many species accumulate in a lineage over time elucidated from molecular phylogenies. One can use fossil data to estimate extinction rates directly and contribute essential information, but their use has limitations. Most data are for marine animals, most studies assess genera, not species, and the temporal resolution of the data is poor. Importantly, they can be used to identify periods when extinction rates exceed speciation events, that is, when lineages shrink in their numbers of species.
We concentrated on insights that may be drawn from molecular phylogenies. Richly detailed phylogenies are readily available for many taxa in many ecosystems. Moreover, it may be possible to estimate speciation and extinction rates separately from a lineage's diversification from one to many species. Problematically, the patterns of branching times in the phylogenies of many lineages result in a zero estimate of extinction rate for the simplest model of constant speciation and extinction. That motivated us to ask two questions. First, what are the upper bounds of extinction rates of lineages derived from this model? Second, how severe are the effects of violating the simple model's assumptions? We created an extensive set of simulations under a wide variety of conditions of changing speciation and extinct rates.

Overall net rates of diversification-the difference between speciation and extinction-are very widely available and simple to calculate, but they seem unpromising. Any given net diversification rate might result from a very high rate of extinction and an only slightly higher rate of speciation. Moreover, there might be many lineages for which extinctions exceed speciation. Of course, if this occurred in the recent (but pre-human) past, then the analyses of detailed phylogenies and the fossil record would demonstrate it. That this is not happening implies that average extinction rates are less than average diversification rates.

\section{Expressing the Magnitude of Present Day Extinctions}

Before 1995, the literature often quoted statistics on current extinctions in terms of species per day. Estimates ranged from a minimum of three (Myers 1989) to "a hundred species per day" (Stork 2010). More than the uncertainties about the extinctions themselves, the 
numbers reflected the wide range of estimates for how many eukaryote species there are (Pimm et al. 2014).

The uncertainty in the species-per-day estimates also posed problems when dealing with critics of environmental concerns who demanded the scientific names of recently extinct species (Stork 2010). Of course, taxonomists have described only a small fraction of species, while the IUCN's Red List (www.iucnredlist.org) has assessed an even smaller fraction of those (approximately 72,000 species). To avoid the necessarily complex caveats for extinctions per day estimates, Pimm et al. (1995) replaced this metric with a proportional rate that they could calculate for a given taxon.

This approach measures extinction rates by following cohorts of species and then tallying how many succumbed subsequently. For example, by 1845 taxonomists had described 5000 bird species. Sixty-one of these were extinct by 2012. Dividing the number of extinct species (61) by the product of 167 years (2012-1845) and total species (5000), one derives the extinction rate as $61 /\left(167^{*} 5000\right)=0.000073$. Multiplying that rate by $1,000,000$ gives an extinction rate of approximately 73 extinctions per million species per year (E/MSY), or $0.073 \%$ per decade (Pimm et al. 2006). In contrast to an uncertain estimate of any day's extinctions, most of which will be unknown to taxonomists, we know these extinctions in detail (Pimm et al. 1995).

\section{Calculating the Background Rate from the Fossil Record}

The fossil record suggests that recognized taxa live from 1 to 10 million years, with some obvious exceptions. Pimm et al. (1995) chose the shorter duration, which gives a background rate of $1 \mathrm{E} / \mathrm{MSY}$, and called it a "benchmark." Barnosky et al. (2011), Harnik et al. (2012), and Alroy (1996) greatly expand on this superficial estimate.

Alroy (1996) estimated 0.165 extinctions of genera per million genera years for Cenozoic mammals. Most paleontological studies assess genera, not species (Flessa \& Jablonski 1985). Harnik et al. (2012) examined marine taxa. Their extinction rate is a dimensionless extinction fraction, the natural logarithm of the fractional survival of genera measured over an average stage length of 7 million years. Converting these fractions to their corresponding rates yields values for the last few million years of 0.06 genera extinctions per million genera for cetaceans, 0.04 for marine carnivores, and from 0.001 (brachiopods) to 0.01 (echinoids) for a variety of marine invertebrates. Put another way, $1 \%$ of echinoid genera are lost per million years.

\section{Species Diversification Rates from Molecular Phylogenies}

Molecular phylogenies provide an appealing alternative to the fossil record's shortcomings because they cover a large range of taxa, periods, and environments. In the

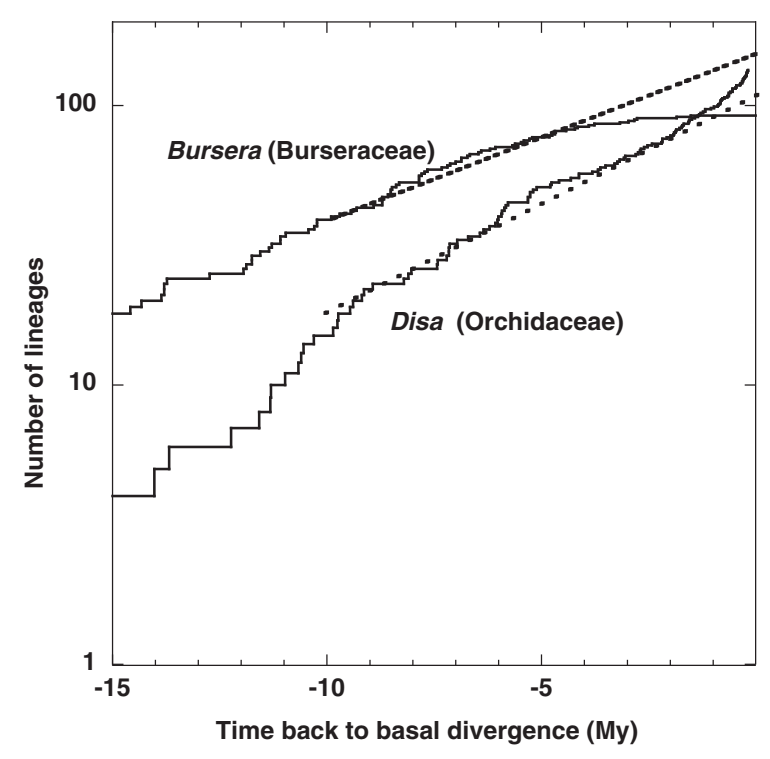

Figure 1. The logarithms of the number of lineages over time for two plant genera and the relationships expected from a simple birth-death model Eq. (1) that assumes speciation and extinction rates are constant through time. The simple model expects an exponential increase in the numbers of lineages over time, or a linear increase on this logarithmic scale (see text). The exponential fit of Disa lineages versus time from 10 to 2 million years before present is shown with the dashed line, thereafter, the observed data are above this line. For Bursera, the dashed black line shows exponential fit of lineages versus time from 10 to 4 million years before present, thereafter, the observed data are below this line.

simplest case, a single lineage grows to a clade size of $N$ species, $E(N)$, during time, $t$, according to

$$
E(N)=\exp \left(r^{*} t\right)
$$

where $r$ is the net diversification rate (i.e., the difference between speciation, $\lambda$, and extinction, $\mu$ ), which can be estimated easily (Kendall 1948; Moran 1953):

$$
(\lambda-\mu)=r=\ln (N) / t .
$$

Can one separately estimate the speciation and extinction rates? With Eq. 1, the plot of the logarithm of the number of lineages through time (LTT) is linear (slope $\lambda-\mu$ ), but with an important qualification. In the limit of the present day, there are no extinctions of the most recent taxa-they have not yet happened. Thus, near the present, the LTT slope should increase and approach $\lambda$, the speciation rate (Nee et al. 1994; Nee 2006). Figure 1 shows an example for South African orchids of the genus Disa.

Practice is considerably more complicated than simple theory (Morlon et al. 2011; Etienne et al. 2012). Lambda and $\mu$ may be time dependent, functionally related, or 
depend on the number of species already present, and they will likely vary from place to place and among taxa. We considered the compilations of McPeek (2008) in which $80 \%$ of the studies have LTT graphs that curve downward on the log-linear scale. Figure 1 shows an example of this for Central American species in the genus Bursera (De-Nova et al. 2012).

Such studies yield a maximum likelihood (ML) estimate of zero extinction, but for all statistical estimates it is standard to determine their probability distributions. Furthermore, we used simulations to explore whether such methods appropriately reconstruct parameter value ranges when the diversification process is more complex than the simple model. Moreover, some phylogenies have features that make them unsuitable for separating speciation and extinction rates. That motivated our selection of phylogenies to analyze.

\section{Methods}

\section{Diversification Rates}

Our choices of data reflected our need to compare estimates of diversification. Phillimore and Price (2008) provide 40 dated phylogenies of bird groups. Ferrer and Good (2012b) provide net diversification rates of all plant families. Valente et al. (2010) searched the literature to find exceptionally high rates of diversification. We use two measures of diversification: Kendall-Moran (Kendall 1948; Moran 1953) and Magallon-Sanderson (Magallon \& Sanderson 2001).

The Kendall-Moran estimator measures the average net diversification Eq. $2 ; t$ is stem age, the time since a lineage diverged from its sister; in contrast, crown age is the time a lineage has been known from its earliest species. This estimator (see below) is corrected by the MagallonSanderson estimator. (In their original publication, Ferrer and Good [2012b] used base 10 for their logarithms, not base e, and later posted a corrigendum [Ferrer \& Good 2012a].)

The Magallon-Sanderson estimator corrects net diversification for non-zero extinction. If extinction is not zero, some extant species will go extinct in the near future, which makes the estimates larger than they should be. One does not know the extinction rate a priori. So, following Magallon and Sanderson (2001), we used arbitrarily low and high extinction fractions $(\mu / \lambda)$ of 0 (i.e., the Kendall-Moran estimate) and of 0.9 and compared the estimates.

\section{Diversification and its Component Speciation and Extinction Rates}

In a perfect world, phylogenies would be complete for all species and evolutionary relationships fully resolved.
Practice falls short. Thus, we included two kinds of relevant data: data from many different groups and from taxonomically diverse lineages and data specifically selected for some taxa.

To cover considerable taxonomic breadth, we used McPeek's (2008) data set of 182 dated phylogenies of Chordata, Mollusca, Magnoliophyta, and Arthropoda from which we excluded small phylogenies. This data set places no particular emphasis on the quality of the phylogenetic trees in terms of number of taxa or dating methodology employed. The fraction of extant species included in each clade is known and high ( $>50 \%)$, however. That property is essential because the signal of extinction in phylogenies-an upturn in an LTT toward the present-is only detectable when one samples a high proportion of extant species. That is also the reason for using a clade-by-clade approach, rather than one based on information available from a single very large supertree that covers considerable taxonomic breadth with few sampled species (e.g., Rabosky et al. 2012). We compared results of the plant phylogenies of McPeek with carefully selected plant phylogenies to confirm that the concerns associated with use of McPeek's data set would not invalidate the results (Supporting Information). We included mammals because the data are typically for a genus or some other subset of species at a taxonomic rank below family.

\section{Mammals and Plants}

We compiled a list of all mammal families with at least five species, based on Wilson and Reeder (2005), and estimated their ages from a published chronogram of all mammals (Fritz et al. 2009). We also identified mammalian orders and families that were at least $90 \%$ resolved in the supertree and extracted these subtrees for use in additional calculations. The latter process yielded 15 subtrees. We used the R package Ape $\mathrm{v} 2.7$ for tree manipulations (Paradis et al. 2004).

We carefully selected 37 dated plant phylogenies based on the inference and taxon sampling methods used so as to ensure branch lengths and divergence times were derived with the best available methods (Supporting Information).

\section{Analyses}

Given the large number of uncertainties in the data on observed species and the origination data we had for them, our overall aim was to generate probability distributions for the parameters given these uncertainties. We did so by employing the constant-rate birth-death model (Nee et al. 1994) with a correction for un-sampled taxa (Bokma 2008), as implemented in a Bayesian framework in the software SubT (Ryberg et al. 2011). 
We created one joint frequency histogram by adding the Markov Chain Monte Carlo samples that the algorithm generated from the analyses of all phylogenies. Summary histograms represent an estimate of the parameter for the entire taxonomic group, while fully accounting for the uncertainty associated with speciation and extinction estimates from any of the individual phylogenies. We also calculated the interval containing $95 \%$ of the observations.

\section{Simulated Data}

We simulated the possible effects of violations of the assumptions of the constant rate birth-death model on estimates of extinction rates from phylogenies in subT. We also assessed the consequences of missing species. We first generated phylogenies under models of constant, lineage-specific, time-slice-specific, and diversity-dependent speciation and extinction rates, and combinations thereof, for a total of 36 diversification scenarios. Then, we pruned one-third of extant tips to reflect incomplete taxon sampling. Subsequently, we estimated the rates of speciation and extinction from the pruned and un-pruned simulated data with two methods based on the assumption of constant rates: the Bayesian implementation (BI) of the constant-rates birthdeath model (which accounts for missing species by treating them as random variables and assumes positive diversification rates), as employed for the empirical phylogenies (subT; Bokma 2008; Ryberg et al. 2011), and a ML estimator (which allows for negative diversification rates and accounts for missing species via its likelihood expression; R-package diversitree [FitzJohn 2012]).

For each simulated phylogeny, we determined whether the estimated $95 \%$ interval of highest posterior density of the subT result included the true, generating value or values of extinction and determined the difference between the estimated rate and these true values. We then combined all results to determine whether there was a systematic bias in over- or underestimation extinction rates compared with their true values. For phylogenies with missing taxa, we compared the performance of the Bayesian and ML methods for accounting for them. Technical details of analyses are discussed in Supporting Information, where we also address further criticisms of these models and how we addressed them.

\section{Results}

\section{Rates of Diversification}

Median rates of diversification were approximately 0.1 species per million species years (Table 1). All but one of the intervals that spanned $95 \%$ of the estimated diversification rates were below 1 species per million species years (Table 1).

\section{Rates of Speciation and Extinction}

These results are complex in their detail and generate numerous caveats that are discussed in Supporting Information. Nonetheless, their key features are simply stated and best viewed in comparison to the summaries of data already published.

The most frequent extinction rate estimates ( $\mu$; Fig. 2 middle panels) were near zero. Median and upper $95 \%$ extinction rates, respectively, were for chordates 0.064 and 0.586 , for plants 0.053 and 0.352 , for arthropods 0.09 and 0.934 , for mammals 0.023 and 0.102 , and for Molluscs 0.135 and 1.672. Median and upper 95\% estimates, respectively, were for chordates 0.241 and 0.751 , for plants 0.352 and 0.877 , for arthropods 0.320 and 0.923 , for mammals 0.257 and 0.778 , and for molluscs 0.357 and 0.825 . For plants, the data set of McPeek yielded fully congruent results to our carefully selected phylogenies, though the former were associated with slightly wider confidence intervals (Supporting Information).

The assumptions underlying the model may not have been met. So, we explored various violations of the assumptions. The results of our simulated data were numerous and complex and are discussed in detail in Supporting Information. We only briefly summarize them here.

Both Bayesian and ML methods often incorrectly inferred extinction rates from individual phylogenies (in $10-49 \%$ of phylogenies, depending on the scenario; Supporting Information). This entailed both over- and underestimations. Overall, without missing species, these effects cancelled each other out to a large extent so that the overall mean or median inferred rates approximated the true, generating values (Supporting Information). When there were missing species, the Bayesian method outperformed the ML method. It only slightly underestimated extinction, whereas the ML method greatly overestimated extinction (Supporting Information). Generally across scenarios, high extinction rates were underestimated, low rates were overestimated, and when a phylogeny contained multiple rates, an intermediate, average rate was found. Although complete phylogenies yielded more accurate results than phylogenies with many missing species, the correct order of magnitude was inferred. Complete phylogenies and phylogenies with missing species yielded congruent results under all 36 combinations of simulation conditions (Supporting Information).

While estimates for individual phylogenies were sometimes in substantial error, estimates averaged across phylogenies were accurate in order of magnitude. 
(a)
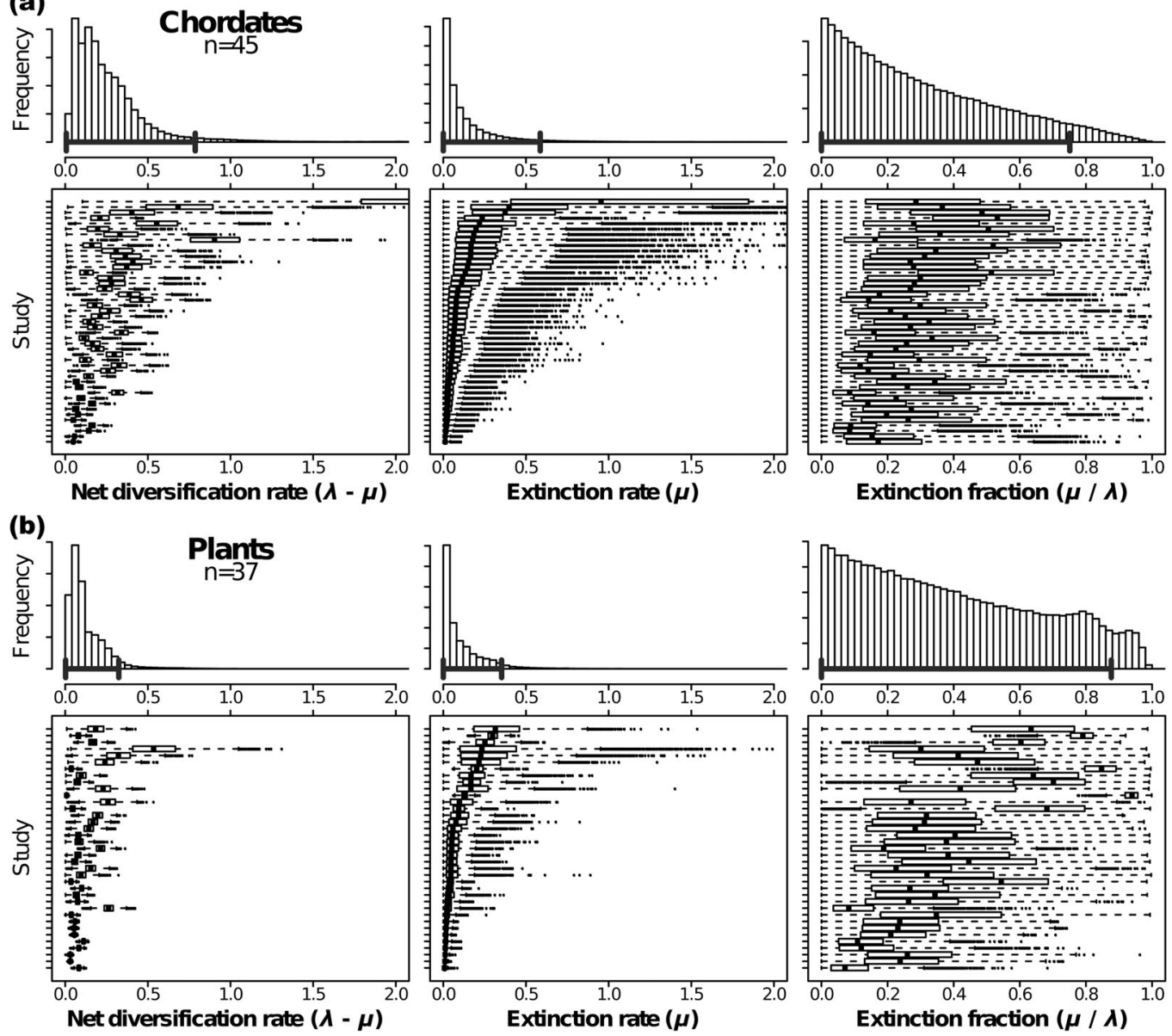

(c)
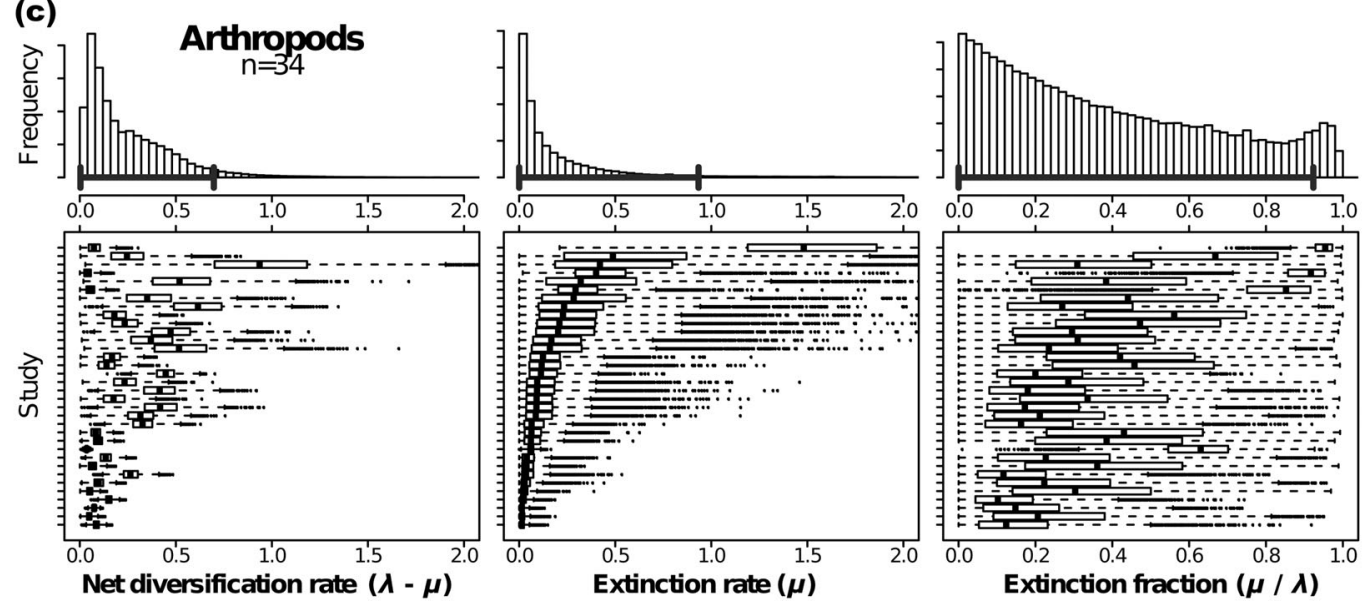

Figure 2. Diversification and extinction rates (expressed as rates per lineage per million years) and extinctionfraction (dimensionless) in descending order by sample size for five taxonomic groups. For each taxonomic group, the top graph shows the frequency distribution of 7500 sample parameter values from each of the phylogenies inthe group. Thus, the data underlying the summary histogram of, for example, mollusks has $8^{*} 7500$ samples. Thebold horizontal line shows the shortest interval containing $95 \%$ of the values. The bottom graphs show descendingorder of extinction rate. We list the individual studies in the order shown in this figure in the SupportingInformation. The median values are the vertical lines within the bars, the 95\% confidence intervals (i.e., the 95\% highest posterior density) are the open boxes, and points are outliers. 

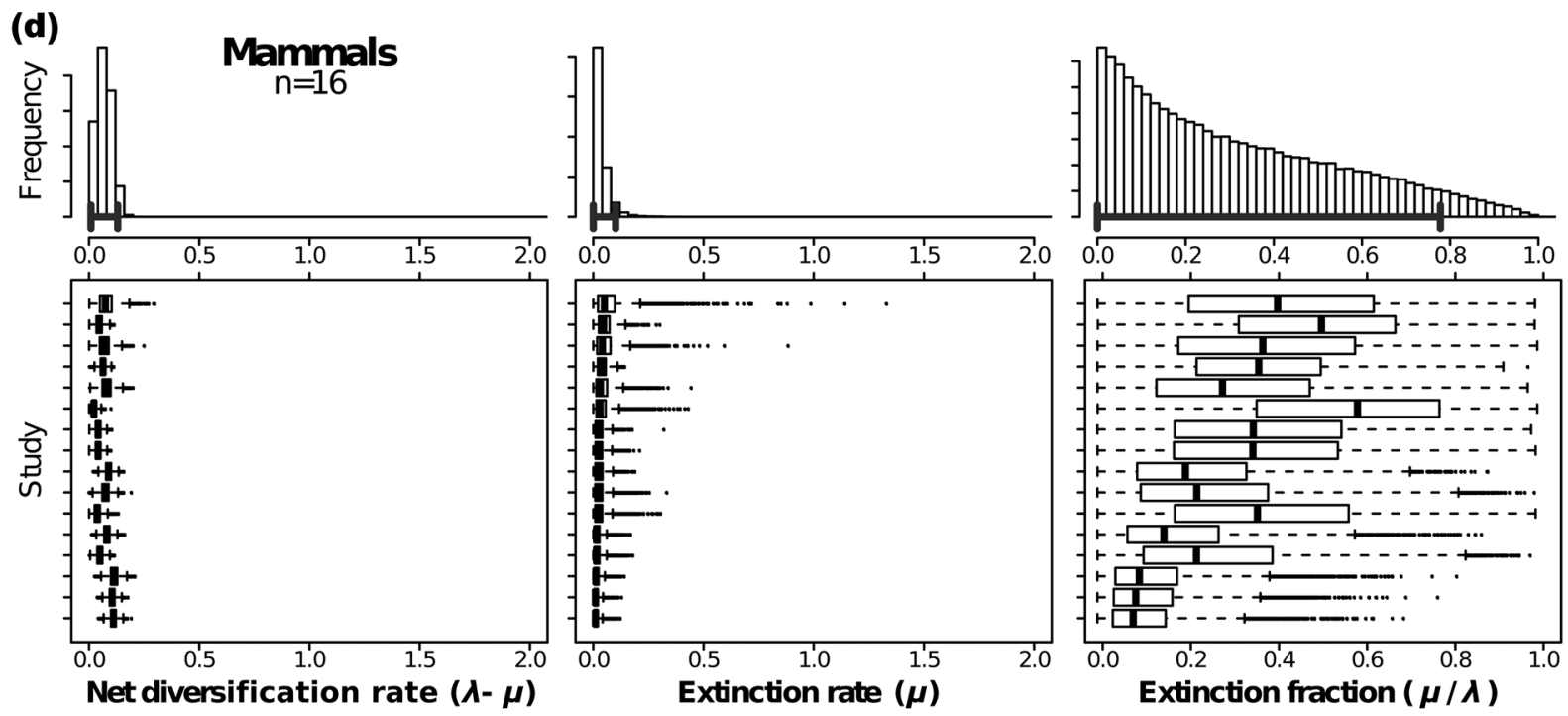

(e)
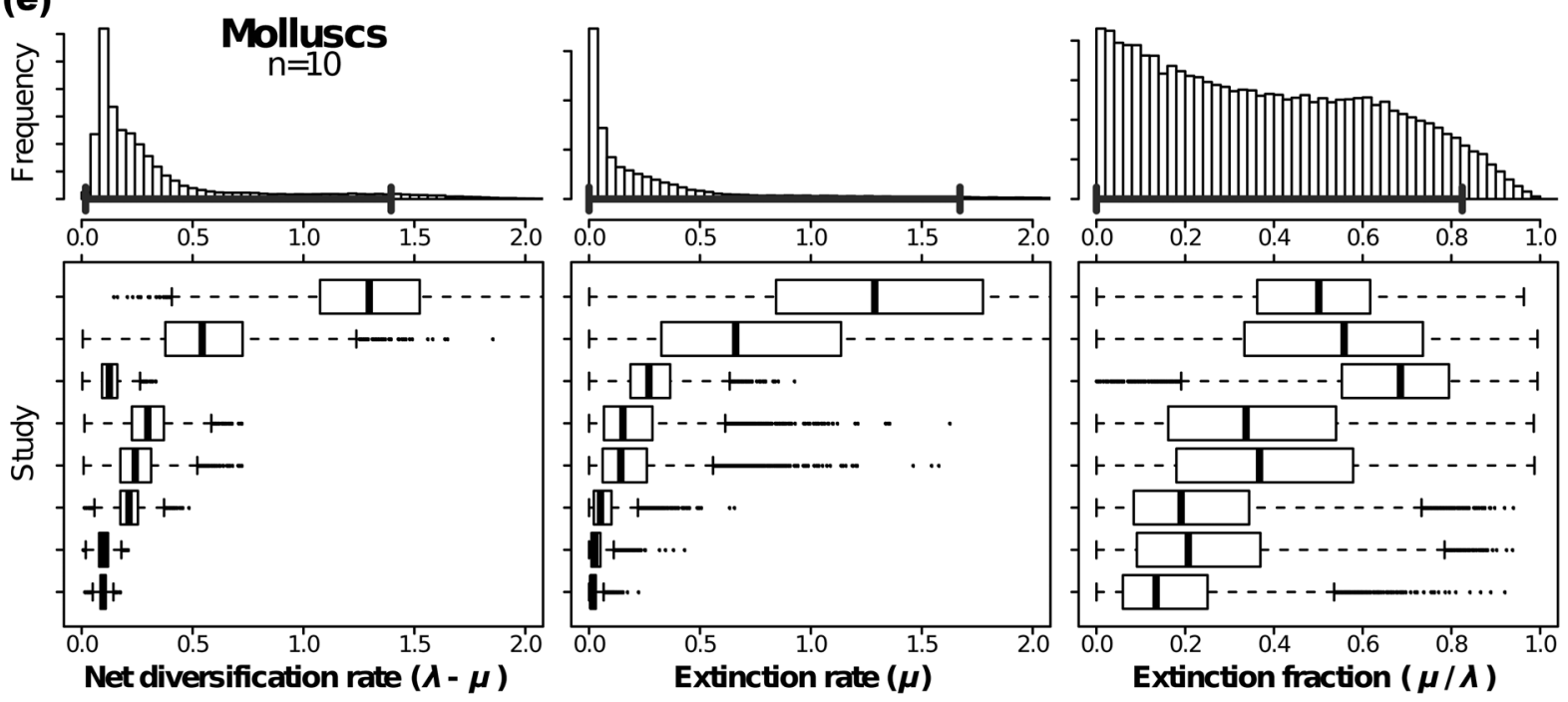

Figure 2. (continued)

\section{Discussion}

\section{Extinction Rates from the Fossil Record}

Fossils provide essential information, but are limited in temporal resolution and taxonomic breadth (Purvis 2008). Estimates based on the fossil record had the obvious bias that taxa identified to species may have been present somewhere before they were first recorded and after they were last recorded. Unless corrected, longevities are potentially underestimated and extinction rates are overestimated (Foote \& Raup 1996).

Interpolating fractional survival based on stages averaging several million years to shorter intervals of a million years is problematical. P. G. Harnik (personal communication) suggests interpolation imputes homogenous rates of extinction across geological stages, while evidence suggests extinction rates are pulsed toward their end (Alroy 2008; Foote 2005). Indeed, changes in floras and faunas often define when one stage ends and the other starts. If so, for millions of years, the rates would have been even lower than values we have presented above and would have been followed by episodes when they were higher. Thus, our earlier estimate of $1 \%$ of echinoid genera lost per million years at an implied constant rate may be incorrect. We can say only that $7 \%$ of echinoid genera are lost over 7 million years.

Comparing rates of generic extinctions with species extinction is complex (Russell et al. 1998). Mammal genera contain an average of 4.4 species. Were all mammal genera to have four species in them, then individual species extinction rates of $0.63 \mathrm{E} / \mathrm{MSY}$ would give the observed generic extinction rate of 0.165 (Alroy 1996). For five species, the species extinction rate would be $0.69 \mathrm{E} / \mathrm{MSY}$. There are two problems with this. Most generic extinctions are likely those in monotypic genera. Second, these calculations are based on an assumption of 
statistical independence. As Russell et al. (1998) show, species extinctions within a genus are highly contingent. Some genera and some places are much more vulnerable to extinction than others. Combined, these considerations would lead to the species extinction rate being close to the generic rate of extinction (i.e., $0.165 \mathrm{E} / \mathrm{MSY}$ ).

In short, when one is comparing the extinction rates of fossils with present biota, one is contrasting genera with species and, of course, typically very different taxa (often marine taxa with terrestrial taxa). Nonetheless, to the extent these comparisons are reasonable, the data strongly suggest that a benchmark of $1 \mathrm{E} / \mathrm{MSY}$ is too high.

\section{Extinction Rates from Phylogenies}

Estimating extinction rates from phylogenies is controversial. First, our selection of phylogenies did not include groups that are both young and small because we would not have had the statistical power to detect anything. Nor did it include groups that are very old and small. For these, we additionally were concerned that strong, yet undetectable fluctuations in rates over time would bias our inference. The groups we included showed strong similarities in the rates of extinction inferred (Fig. 2). We do not know if groups we could not study would differ greatly. The advantage of including larger groups is that our results are informative for many species, hence, we hope representative.

Second, as Rabosky (2009b) showed in his uncompromisingly titled paper "Extinction Rates Should Not Be Estimated from Molecular Phylogenies," ML estimates can produce an overestimation of the real extinction rate if among-lineage variation in diversification rate increases. We addressed this concern in two ways. We excluded large phylogenies ( $>500$ species) for which this issue may be particularly problematic. Then, we provided a range of possible values for each phylogeny by means of Bayesian inference. The expectation is that when there is conflict within the subsets of data on the relative extinction rate (e.g., high or low), a Bayesian analysis would provide the range of possible solutions as output. Alternative approaches to accommodate such among-lineage rate variation by splitting a phylogeny into multiple rate partitions (Alfaro et al. 2009; Rabosky et al. 2013) pose other statistical challenges (Supporting Information). Importantly, if Rabosky's (2009a) concerns apply, it means our estimates of extinction rates are too high and the comparisons to present day rates too low. In short, his concerns make our results conservative.

Third and conversely, many phylogenies showed a slower than exponential increase in lineages over time near the present. Ecological factors may limit the maximum size a clade may achieve (Rabosky \& Lovette 2008; Morlon et al. 2010; Morlon et al. 2011; Etienne \& Rosindell 2012; Etienne et al. 2012). Price et al. (2014) provide a detailed example for Himalayan birds that argues niche saturation forces such slower than exponential patterns. In addition, speciation takes time to become complete (Etienne \& Rosindell 2012).

Whatever the causes, the consequence of this slowing is that it obscures on-going extinctions and so makes our estimates of their rate too low. Indeed, for Bursera (Fig. 1), it seems improbable a priori that their extinction rate has been exactly zero for 7 million years.

To address these concerns, we undertook numerous simulations of known diversifications, with varying fractions of species removed from these modeled clades and, in some cases, different rates of diversification (Supporting Information). At best, our simulations demonstrated that the underestimation of extinction due to complex diversification processes may be slight. We recovered the correct order of magnitude of absolute extinction across replicate phylogenies, even though individual estimates are associated with large uncertainties. Our findings underline the recent conclusion that phylogenies of extant taxa contain some information on extinction rates (Pyron \& Burbrink 2013), even when assumptions of simple models are not fully met.

Finally, taxonomists may fall short of recognizing all lineages that will give rise to new species in the future (Phillimore \& Price 2008). The entirely arbitrary taxonomic decision of whether to group geographically isolated populations as one species or split them into several recently derived species affects estimates of extinction rates.

Despite those difficulties, an important conclusion emerges. Of the 140 phylogenies we analyzed (Fig. 2), all but four had median estimated extinction rates of $<0.4 \mathrm{E} / \mathrm{MSY}$ and only two (one arthropod and one mollusk) had rates $>1$, and those were $<1.5$. These estimates match those of Weir and Schluter (2007), who estimated bird and mammal extinctions at $0.08 \mathrm{E} / \mathrm{MSY}$ at the equator-where there are the most species-and at $\sim 0.4-0.6 \mathrm{E} / \mathrm{MSY}$ at $50^{\circ}$ latitude-where there are fewer species. (They based their estimates on the ages of a large number of sister species divergences of New World birds and mammals.) Thus, despite the methodological hurdles and the potentially confounding whims of taxonomists, there is consistent evidence that background extinction rates are $<1$ extinction per million species-years and likely much less than this.

\section{Diversification Rates}

Median diversification rates were from $\sim 0.05$ to $\sim 0.2$ new species per species per million years for a disparate group of animals and plants (Table 1). Diversification rates $>1.0$ were exceptional. Valente et al. (2010) explicitly addressed the issue of how fast taxa can diversify. They analyzed the genus Dianthus (carnations, Caryophyllaceae) and found net diversification rates of up to 16 new species per species per million years. This 
Table 1. Diversification rates for selected taxa derived from different methods of analysis.

\begin{tabular}{|c|c|c|c|c|}
\hline Study & Metbod $^{a}$ & $n$ & Median & $95 \%$ \\
\hline Plants $[22]^{b}$ & M-S & 204 & 0.060 & $0.002-0.189$ \\
\hline \multirow[t]{2}{*}{ Birds [21] } & K-M & 45 & 0.216 & $0.092-0.543$ \\
\hline & M-S & 45 & 0.147 & $0.061-0.393$ \\
\hline McPeek Chordata $^{b}$ & this study & 45 & 0.204 & $0.007-0.787$ \\
\hline Plants (see text) ${ }^{b}$ & this study & 37 & 0.088 & $0.002-0.324$ \\
\hline McPeek Arthropods ${ }^{b}$ & this study & 34 & 0.173 & $0.003-0.698$ \\
\hline McPeek Mammals $^{b}$ & this study & 16 & 0.066 & $0.009-0.13$ \\
\hline McPeek Mollusca $^{b}$ & this study & 8 & 0.135 & $0.018-1.395$ \\
\hline
\end{tabular}

a Abbreviations: K-M, Kendall-Moran estimator; M-S, Magallon-Sanderson estimator (see text). The K-M and M-S estimators are applied to data for plants from Ferrer and Good (2012b), for birds from Phillimore and Price (2008), and for mammals from this study. The estimation approach applied to the remaining data was implemented in subT as described in the text for data on 37 plant taxa (selected for this study), arthropods, mollusks, and chordates (other than birds and mammals) from McPeek (2008) and for a subset of the mammal data.

${ }^{b}$ Crown ages (see text) were used.

puts them well above 11 other plant groups, the highest rate of which was for Andean Lupinus (lupins, Fabaceae) at approximately 2 (Hughes \& Eastwood 2006; Koenen et al. 2013). For birds, the record holders are the Southeast Asian Zosterops (White-eyes, Zosteropidae), at 2.6 new species per species per million years. Others classify some of these species as subspecies, which would reduce that rate.

Valente et al. (2010) also discuss the cichlids of east African lakes and estimate stem diversification of up to six new species per species per million years for Lake Malawi cichlids. They show that rates roughly ten times these for Lake Victoria cichlids are possible if the $\sim 500$ species now present are all descended from just one ancestor after the lake dried out 14,700 years ago. To achieve such rates, however, one must completely exclude the possibility of several species surviving that desiccation in refugia. An additional example is the rapid divergence of Enallagma damselflies that have added 23 new species from 7 lineages in the last 250,000 years (Turgeon et al. 2005). In contrast are lineages such as Ginkgo biloba that appear to have changed little since the Jurassic (Zhou \& Zheng 2003).

\section{Synthesis}

We reviewed three lines of evidence toward obtaining an order of magnitude estimate of the background rate of extinction. The fossil data set a broad expectation of how fast such species go extinct. Separating extinction and speciation rates from phylogenies is methodologically difficult. We selected phylogenies carefully so as to find credible estimates and used simulations that suggested that the correct order of magnitude is recovered, even when the diversification process is complex. In general, we estimated extinction rates that were typically much smaller than Pimm et al.'s (1995) benchmark of 1 E/MSY. There are statistical uncertainties, but generally high background extinction rates would surely be noticeable either in some phylogenies or within the range of uncertainties in all of them.

Rates of diversification are less direct, but there are many compilations of them across different taxa and ecosystems. Diversification rates were $\sim 0.05$ to $\sim 0.2$ new species per species per million years, with exceptional rates of $>1$. The question is what does these tell us about extinction rates.

The fossil record shows that overall species richness increases over time (Rosenzweig 1995). Certainly, some clades are shrinking (examples in Quental and Marshall [2011]), but fewer are shrinking than increasing. The direct estimates of extinction rates from phylogenies estimated above are also low. Our simulation models showed that when averaged across a set of phylogenies, the models placed these rates within an order of magnitude. In short, what we saw in observed phylogenies also precluded high extinction rates.

Simply, there is no widespread evidence for high recent extinction rates from either the fossil record or from molecular phylogenies; thus, in general extinction rates cannot exceed diversification rates. Combining the evidence from fossils, the separation of speciation and extinction rates from molecular phylogenies, and from overall diversification rates, we conclude that the benchmark estimate of the natural background rate of $1 \mathrm{E} / \mathrm{MSY}$ extinctions per million species per years is too high. A more defensible estimate should be closer to 0.1 E/MSY, whereupon current extinction rates are 1,000 times higher than the natural background and future rates of extinction are likely to be 10,000 times higher. 


\section{Acknowledgments}

We thank A. Antonelli, A. D. Barnosky, P. G. Harnik, M. McPeek, G. J. Russell, M. Ryberg, T. Price, D. Silvestro, and $\mathrm{D}$. Tittensor for comments and discussion.

\section{Supporting Information}

Additional numerical details of data in Figure 2 (Appendix S1), data sources (Appendix S2), list of selected mammal studies (Appendix S3), list of plant studies from McPeek (2008) (Appendix S4), details of procedure used to select plant phylogenies (Appendix S5), details on use of program SubT (Appendix S6), model criticisms and how we addressed them (Appendix S7), criteria used to select phylogenies (Appendix S8), details of the simulation approach (Appendix S9), absolute extinction rates estimated from complete trees and from trees with onethird missing species (Appendix S10), detailed results of complete phylogenies (Appendix S11), and additional references (Appendix S12). The authors are solely responsible for the content and functionality of these materials. Queries (other than absence of the material) should be directed to the corresponding author.

\section{Literature Cited}

Alfaro, M. E., F. Santini, C. Brock, H. Alamillo, A. Dornburg, D. L. Rabosky, G. Carnevale, and L. J. Harmon. 2009. Nine exceptional radiations plus high turnover explain species diversity in jawed vertebrates. Proceedings of the National Academy of Sciences 106:1341013414.

Alroy, J. 1996. Constant extinction, constrained diversification, and uncoordinated stasis in North American mammals. Palaeogeography, Palaeoclimatology, Palaeoecology 127:285-311.

Alroy, J. 2008. Dynamics of origination and extinction in the marine fossil record. Proceedings of the National Academy of Sciences 105:11536-11542.

Barnosky, A. D., N. Matzke, S. Tomiya, G. O. U. Wogan, B. Swartz, T. B. Quental, C. Marshall, J. L. McGuire, E. L. Lindsey, and K. C. Maguire. 2011. Has the earth's sixth mass extinction already arrived? Nature 471:51-57.

Bokma, F. 2008. Bayesian estimation of speciation and extinction probabilities from (in) complete phylogenies. Evolution 62:2441-2445.

De-Nova, J. A., R. Medina, J. C. Montero, A. Weeks, J. A. Rosell, M. E. Olson, L. E. Eguiarte, and S. Magallón. 2012. Insights into the historical construction of species-rich Mesoamerican seasonally dry tropical forests: the diversification of Bursera (Burseraceae, Sapindales). New Phytologist 193:276-287.

Etienne, R. S., B. Haegeman, T. Stadler, T. Aze, P. N. Pearson, A. Purvis, and A. B. Phillimore. 2012. Diversity-dependence brings molecular phylogenies closer to agreement with the fossil record. Proceedings of the Royal Society B: Biological Sciences 279:1300-1309.

Etienne, R. S., and J. Rosindell. 2012. Prolonging the past counteracts the pull of the present: protracted speciation can explain observed slowdowns in diversification. Systematic Biology 61:204-213.
Ferrer, M. M., and S. V. Good. 2012a. Correction. Annals of Botany 110:1079-1081.

Ferrer, M. M., and S. V. Good. 2012b. Self-sterility in flowering plants: preventing self-fertilization increases family diversification rates. Annals of Botany 110:535-553

FitzJohn, R. G. 2012. Diversitree: comparative phylogenetic analyses of diversification in R. Methods in Ecology and Evolution 3:1084-1092.

Flessa, K. W., and D. Jablonski. 1985. Declining Phanerozoic background extinction rates: Effect of taxonomic structure? Nature 313:216-218.

Foote, M. 2005. Pulsed origination and extinction in the marine realm. Paleobiology 31:6-20

Foote, M., and D. M. Raup. 1996. Fossil preservation and the stratigraphic ranges of taxa. Paleobiology 22:121-140.

Fritz, S. A., O. R. P. Bininda Emonds, and A. Purvis. 2009. Geographical variation in predictors of mammalian extinction risk: big is bad, but only in the tropics. Ecology Letters 12:538-549.

Gore, A. 2006. An inconvenient truth: The planetary emergency of global warming and what we can do about it. Rodale Books, New York.

Harnik, P. G., H. K. Lotze, S. C. Anderson, Z. V. Finkel, S. Finnegan, D. R. Lindberg, L. H. Liow, R. Lockwood, C. R. McClain, and J. L. McGuire. 2012. Extinctions in ancient and modern seas. Trends in Ecology \& Evolution 27:608-617.

Hughes, C., and R. Eastwood. 2006. Island radiation on a continental scale: exceptional rates of plant diversification after uplift of the Andes. Proceedings of the National Academy of Sciences 103:10334-10339.

Kendall, D. G. 1948. On the generalized "birth-and-death" process. The Annals of Mathematical Statistics 19:1-15.

Koenen, E., J. de Vos, G. Atchison, M. Simon, B. Schrire, E. de Souza, L. de Queiroz, and C. Hughes. 2013. Exploring the tempo of species diversification in legumes. South African Journal of Botany 89:19-30.

Magallon, S., and M. J. Sanderson. 2001. Absolute diversification rates in angiosperm clades. Evolution 55:1762-1780.

McPeek, M. A. 2008. The ecological dynamics of clade diversification and community assembly. The American Naturalist 172:E270-E284.

Moran, P. 1953. The estimation of the parameters of a birth and death process. Journal of the Royal Statistical Society. Series B (Methodological) 15:241-245.

Morlon, H., T. L. Parsons, and J. B. Plotkin. 2011. Reconciling molecular phylogenies with the fossil record. Proceedings of the National Academy of Sciences 108:16327-16332.

Morlon, H., M. D. Potts, and J. B. Plotkin. 2010. Inferring the dynamics of diversification: a coalescent approach. PLoS Biology 8(9). DOI:10.1371/ journal.pbio.1000493.

Myers, N. 1989. Extinction rates past and present. BioScience 39:39-41.

Nee, S. 2006. Birth-death models in macroevolution. Annual Review of Ecology, Evolution, and Systematics 37:1-17.

Nee, S., E. C. Holmes, R. M. May, P. H. Harvey, S. Nee, E. C. Holmes, R. M. May, and P. H. Harvey. 1994. Extinction rates can be estimated from molecular phylogenies. Philosophical Transactions of the Royal Society of London. Series B: Biological Sciences 344: 77-82.

Paradis, E., J. Claude, and K. Strimmer. 2004. APE: analyses of phylogenetics and evolution in $\mathrm{R}$ language. Bioinformatics 20: 289-290.

Phillimore, A. B., and T. D. Price. 2008. Density-dependent cladogenesis in birds. PLoS biology 6. DOI: 10.1371/journal.pbio.0060071.

Pimm, S., P. Raven, A. Peterson, Ç. H. Şekercioğlu, and P. R. Ehrlich. 2006. Human impacts on the rates of recent, present, and future bird extinctions. Proceedings of the National Academy of Sciences 103:10941-10946. 
Pimm, S., G. J. Russell, J. Gittleman, and T. M. Brooks. 1995. The future of biodiversity. Science 269:347-350.

Pimm, S. L., C. N. Jenkins, R. Abell, T. M. Brooks, J. L. Gittleman, L. Joppa, P. H. Raven, C. M. Roberts, and J. O. Sexton. 2014. The biodiversity of species, their rates of extinction, distribution, and protection. Science 344: 987. DOI: 10.1126/science. 1246752

Price, T. D., et al. 2014. Niche filling slows the diversification of Himalayan songbirds. Nature 509:222-225.

Purvis, A. 2008. Phylogenetic approaches to the study of extinction. Annual Review of Ecology, Evolution, and Systematics 39:301-319.

Pyron, R. A., and F. T. Burbrink. 2013. Phylogenetic estimates of speciation and extinction rates for testing ecological and evolutionary hypotheses. Trends in Ecology \& Evolution 28:729-736.

Quental, T. B., and C. R. Marshall. 2011. The molecular phylogenetic signature of clades in decline. PloS one 6. DOI: 10.1371/journal. pone. 0025780

Rabosky, D. L. 2009a. Ecological limits and diversification rate: alternative paradigms to explain the variation in species richness among clades and regions. Ecology Letters 12:735-743.

Rabosky, D. L. 2009b. Extinction rates should not be estimated from molecular phylogenies. Evolution 64:1816-1824.

Rabosky, D. L., and I. J. Lovette. 2008. Density-dependent diversification in North American wood warblers. Proceedings of the Royal Society B: Biological Sciences 275:2363-2371.

Rabosky, D. L., F. Santini, J. Eastman, S. A. Smith, B. Sidlauskas, J. Chang, and M. E. Alfaro. 2013. Rates of speciation and morphological evolution are correlated across the largest vertebrate radiation. Nature Communications 4:1958. DOI: 10.1038/ncomms2958.
Rabosky, D. L., G. J. Slater, and M. E. Alfaro. 2012. Clade age and species richness are decoupled across the Eukaryotic tree of life. PLoS Biology 10(8). DOI:10.1371/journal.pbio.1001381

Rosenzweig, M. L. 1995. Species diversity in space and time. Cambridge University Press, Cambridge.

Russell, G. J., T. M. Brooks, M. M. McKinney, and C. G. Anderson. 1998. Present and future taxonomic selectivity in bird and mammal extinctions. Conservation Biology 12:1365-1376.

Ryberg, M., R. H. Nilsson, and P. B. Matheny. 2011. DivBayes and SubT: exploring species diversification using Bayesian statistics. Bioinformatics 27:2439-2440.

Stork, N. E. 2010. Re-assessing current extinction rates. Biodiversity and Conservation 19:357-371.

Turgeon, J., R. Stoks, R. A. Thum, J. M. Brown, and M. A. McPeek. 2005. Simultaneous quaternary radiations of three damselfly clades across the Holarctic. The American Naturalist 165:E78-E107.

Valente, L. M., V. Savolainen, and P. Vargas. 2010. Unparalleled rates of species diversification in Europe. Proceedings of the Royal Society B: Biological Sciences 277:1489-1496.

Weir, J. T., and D. Schluter. 2007. The latitudinal gradient in recent speciation and extinction rates of birds and mammals. Science 315:1574-1576.

Wilson, D. E., and D. A. M. Reeder. 2005. Mammal species of the world: a taxonomic and geographic reference. Johns Hopkins University Press, Baltimore, Maryland.

Zhou, Z., and S. Zheng. 2003. Palaeobiology: the missing link in Ginkgo evolution. Nature 423:821-822. 